\title{
SELEÇÃO DE SEMENTES DE MILHO DURANTE A SIMULAÇÃO DA SEMEADURA COM DISCO PERFURADO HORIZONTAL
}

\author{
ROBERTO JASPER ${ }^{1}$, MÔNICA JASPER ${ }^{2}$, LUIZ C. GARCIA ${ }^{3}$
}

\begin{abstract}
RESUMO: Teve-se o objetivo de verificar a possível seleção de sementes de milho - arredondadas e achatadas - no processo de semeadura com disco perfurado horizontal, bem como as consequiências na distribuição longitudinal. Os registros dos dados deram-se pela avaliação visual de duas pessoas, com contador manual, no final da esteira carpetada em movimento de 1,54 $\mathrm{m} \mathrm{s}^{-1}$, com 4,60 m de perspectiva para avaliação. Assim, um sensor registrava o número de orifícios do disco horizontal que devia passar pelo tubo condutor, e os espaçamentos falhos e múltiplos eram computados por pessoas diferentes. Os espaçamentos aceitáveis foram obtidos pela subtração dos espaçamentos falhos e múltiplos do total contabilizado. A medição do comprimento e espessura das sementes foi realizada com auxílio de paquímetro. Não houve alterações significativas nas variáveis estudadas, até a passagem de 55 mil orifícios do disco horizontal pelo tubo condutor; portanto, não houve seleção de sementes de milho durante a simulação do processo de semeadura.
\end{abstract}

PALAVRAS-CHAVE: distribuição longitudinal, tamanho da semente.

\section{SELECTION OF CORN SEEDS DURING THE SIMULATION OF SEEDING WITH A HORIZONTAL SEED PLATE}

\begin{abstract}
The aim at this work was to verify the possibility of selection of corn seeds - round and flat - in the process of seeding with a horizontal seed plate, as well as the consequences for longitudinal distribution. Data was registered by using visual evaluation of two people that were allocated at the carpeted belt moving at $1.54 \mathrm{~m} \mathrm{~s}^{-1}$, with a perspective of $4.60 \mathrm{~m}$ for evaluation. A sensor registered the number of holes in the horizontal plate that was supposed to pass through the seed drop tube this way the failing and multiple spacing were registered by different people. Acceptable spacing was obtained by the subtraction of failing and multiple spacing off the total number. Using a caliper the measurement of length and thickness of the seeds was done. The variables analyzed were: skips, multiples and acceptable spacing, and seed length and thickness. There were no significant changes in the variables up to the point when 55,000 holes of the horizontal plate had passed by the seed drop tube. Therefore, there was no corn seed selection during the simulation of seeding process.
\end{abstract}

KEYWORDS: longitudinal distribution, seed size.

\section{INTRODUÇÃO}

A correta distribuição longitudinal das sementes é uma das características que mais contribui para a obtenção de estande adequado de plantas e de boa produtividade das culturas. Na semeadura realizada com semeadoras-adubadoras, diversos fatores interferem no estabelecimento do estande adequado de plantas, destacando-se entre eles a uniformidade das sementes e o mecanismo dosador (KURACHI et al., 1989).

Com o intuito de uniformizar e facilitar a semeadura, as sementes de milho são classificadas durante o beneficiamento quanto ao tamanho, sendo separadas por peneiras (PINHO et al., 1995).

\footnotetext{
${ }^{1}$ Eng ${ }^{\mathrm{o}}$ Agrônomo, Professor, Universidade Estadual de Ponta Grossa - UEPG, Ponta Grossa - PR, Fone: (0XX42) 229.5010, jasper@socidisco.com.br

2 Acadêmica de Agronomia, Universidade Estadual de Ponta Grossa - UEPG, Ponta Grossa, PR.

${ }^{3}$ Eng ${ }^{\circ}$ Agrônomo, Pós-Graduando em Proteção de Plantas, Faculdade de Ciências Agronômicas, UNESP, Botucatu - SP.

Recebido pelo Conselho Editorial em: 29-9-2003
}

Aprovado pelo Conselho Editorial em: 19-4-2006 
Com relação aos mecanismos dosadores, os mais comuns e de menor custo são os munidos com disco perfurado (ROCHA et al., 1992).

KRZYZANOWSKI et al. (1991), FEY (1998), JUSTINO et al. (1998) e SANTOS \& WEIRICH NETO (1998) reportam problemas quanto à homogeneidade das sementes. Sendo o orifício do disco horizontal rígido e as sementes com variação no tamanho, há a possibilidade de seleção das sementes maiores no decorrer do processo de semeadura. As conseqüências seriam a elevação na dificuldade de adequação aos orifícios do disco dosador, alteração na qualidade da distribuição longitudinal e aumento dos danos mecânicos. SILVA \& MARCOS FILHOS (1982) e PINHO et al. (1995) encontraram diferenças significativas na qualidade da instalação da cultura, conforme o formato da semente.

Estudos indicam que a velocidade tangencial do disco deve estar no máximo a $0,29 \mathrm{~m} \mathrm{~s}^{-1}$ (DELAFOSSE, 1986, PACHECO et al., 1996, SILVA et al., 2000). Segundo KEPNER et al. (1978), o diâmetro das células distribuidoras deve ser 10\% maior que a máxima dimensão das sementes empregadas e a espessura igual à espessura média da semente, para que haja boa distribuição longitudinal. Em semeadura de precisão, os espaçamentos aceitáveis devem estar acima de 91\%, em ensaios executados em condições de laboratório (IRLA \& HEUSSER, 1991).

A literatura consultada não traz informações sobre a existência de seleção de sementes maiores e as possíveis consequiências na distribuição longitudinal ao longo do processo de semeadura com disco perfurado horizontal. Assim sendo, o objetivo deste trabalho foi verificar a seleção de sementes de milho - arredondadas e achatadas - no processo de semeadura com disco perfurado horizontal, bem como as conseqüências na distribuição longitudinal.

\section{MATERIAL E MÉTODOS}

O experimento foi realizado nas instalações da empresa Socidisco, sediada em Ponta Grossa PR, em julho de 2003. O critério de escolha dos híbridos e peneiras deu-se pela elevada variação no tamanho de sementes, selecionando-se os híbridos 3021 (peneira R2M e lote 23857) e D766 (peneira C2L e lote PJ2944D131). Trabalhou-se com sementes arredondadas e achatadas devido às diferenças significativas na qualidade da instalação da cultura encontradas por SILVA \& MARCOS FILHOS (1982) e PINHO et al. (1995).

Os discos perfurados horizontais e os anéis empregados seguiram as indicações das empresas produtoras das sementes. Assim, para o híbrido 3021, utilizaram-se o disco NA11,5R e o anel VDE001. Já a recomendação para o híbrido D766 foi o disco MRE14R, com anel AM000.

O disco horizontal NA11,5R possuía $189,5 \mathrm{~mm}$ de diâmetro, 4,0 $\mathrm{mm}$ de espessura e 28 perfurações. As perfurações - em formato cônico - possuíam 11,5 e 12,5 mm de diâmetro nas faces superior e inferior do disco, respectivamente. O anel VD001 apresentava as dimensões de 189,5 m de diâmetro e 4,3 $\mathrm{mm}$ de espessura, com rebaixo na área de contato com a semente de $1,8 \mathrm{~mm}$. A abertura no anel para passagem das sementes tinha $27,8 \times 16,6 \mathrm{~mm}$.

O disco horizontal MRE14R possuía 189,5 mm de diâmetro, 4,0 $\mathrm{mm}$ de espessura e 28 perfurações. As perfurações, em formato cônico, possuíam 14,0 e 15,0 mm de diâmetro nas faces superior e inferior do disco, respectivamente. O anel AM000 apresentava as dimensões de 189,5 m de diâmetro e 4,3 mm de espessura. A abertura no anel para passagem das sementes tinha $27,8 \mathrm{x}$ $16,6 \mathrm{~mm}$.

Optou-se pelo delineamento experimental inteiramente casualizado, com três tratamentos e dez repetições. Os tratamentos consistiram na avaliação da distribuição longitudinal e tamanho das sementes após a passagem de 2 mil, 30 mil e 55 mil orifícios do disco pelo tubo condutor de sementes.

Os testes de simulação da distribuição longitudinal de sementes ocorreram em uma máquina com suporte para acoplamento do sistema dosador de semeadora de disco perfurado horizontal fixado numa estrutura metálica, na extremidade de uma esteira carpetada de 0,20 x 9,66 m. O 
sistema foi acionado por motor elétrico de $0,74 \mathrm{~kW}$. A velocidade tangencial do disco foi de $0,14 \mathrm{~m} \mathrm{~s}^{-1}$ e a de deslocamento da esteira manteve-se constante em 1,54 $\mathrm{m} \mathrm{s}^{-1}$, portanto dentro das recomendações de DELAFOSSE (1986), PACHECO et al. (1996) e SILVA et al. (2000). A máquina estava munida com sensor que registrava o número de orifícios do disco horizontal que passavam pelo tubo que conduzia a semente do mecanismo dosador à esteira. A relação de engrenagens permitia a passagem de um orifício do disco pelo tubo condutor de sementes a cada 0,17 segundos. O tubo condutor apresentava comprimento de $0,35 \mathrm{~m}$ e aberturas de $45 \times 30$ (próximo ao disco) e 30 x 15 mm (próximo à esteira).

Os registros dos dados deram-se pela avaliação visual de duas pessoas, com contador manual, no final da esteira carpetada em movimento, com 4,60 m de perspectiva para avaliação. Assim, o sensor registrava o número de orifícios do disco horizontal que devia passar pelo tubo condutor, e os espaçamentos falhos e múltiplos eram computados por pessoas diferentes. Os espaçamentos aceitáveis foram obtidos pela subtração dos espaçamentos falhos e múltiplos do total contabilizado. As avaliações foram embasadas nas recomendações da ASSOCIAÇÃO BRASILEIRA DE NORMAS TÉCNICAS (1989), que considera como aceitáveis todos os espaçamentos entre sementes de 0,5 e 1,5 vez o espaçamento médio esperado (EM) de 0,26 m. Os valores obtidos fora desse limite foram considerados como espaçamentos falhos (acima de 1,5 vez EM) ou múltiplos (abaixo de 0,5 vez EM). Os dados foram confrontados pela comparação do número de orifícios do disco horizontal que passaram pelo sistema dosador, computados pelo sensor, e a quantidade de sementes depositadas no mesmo período do processo.

Com o auxílio de um paquímetro metálico Vonder $150 \mathrm{~mm}$, após o registro dos dados sobre distribuição longitudinal, mediram-se, em quatro repetições, o comprimento e a espessura das sementes. A coleta das sementes para medição ocorreu sempre na área próxima ao gatilho raspador, sem a retirada do reservatório da máquina. Após a medição, as sementes eram retornadas ao local de onde tinham sido retiradas, sendo o reabastecimento sempre realizado após a recolocação das sementes mensuradas no reservatório.

O sistema dosador empregado teve as folgas entre disco, anel-base e base intermediária corrigidas por um anel metálico móvel fixado na base intermediária. $\mathrm{O}$ espaço entre o disco e os gatilhos raspadores manteve-se em $1,5 \mathrm{~mm}$. Todas as coletas de dados deram-se com no mínimo 4,0 kg de sementes no reservatório, para atender às recomendações de CHHINNAN et al. (1975) e GAZZOLA (1989).

O tamanho da amostra foi determinado com base no método proposto por KRANZ (1988), que leva em consideração a estabilização da média e/ou desvio-padrão da variável estudada. Aplicou-se o teste de Hartley para verificação da homocedasticidade das variâncias. Os valores levantados foram submetidos à análise estatística, empregando-se os testes "F" e de regressão polinomial (BANZATTO \& KRONKA, 1995).

\section{RESULTADOS E DISCUSSÃO}

A análise da distribuição longitudinal das sementes teve o tamanho das amostras definido em 700 e 500 orifícios por parcela, para sementes arredondadas (3021, peneira R2M) e achatadas (D766, peneira C2L), respectivamente. Em se tratando do tamanho das sementes, a amostra foi limitada em 50 unidades para os dois formatos. A partir desses valores, houve estabilização da média e do desvio - padrão das variáveis em estudo, contemplando o método proposto por KRANZ (1988).

O teste de Hartley apontou a homocedasticidade das variâncias dos dados coletados sobre distribuição longitudinal e tamanho das sementes, com grau de confiança superior a 95\% de probabilidade. Portanto, não houve necessidade de transformação das médias para a aplicação do teste " $F$ ". Ao se analisar a distribuição longitudinal, verificou-se que não houve diferenças significativas para a variável "espaçamentos falhos", pelo teste "F", com a passagem de até 55 mil 
orifícios do disco perfurado horizontal pelo tubo condutor (Tabela 1). Desse modo, não houve necessidade do emprego da regressão polinomial.

TABELA 1. Espaçamentos falhos para as sementes de milho arredondadas (híbrido 3021, peneira R2M) e achatadas (híbrido D766, peneira C2L) durante a simulação da semeadura com os discos perfurados horizontais NA11,5R (anel VDE001) e MRE14R (anel AM000), respectivamente.

\begin{tabular}{ccc}
\hline Número de Orifícios do Disco Perfurado & \multicolumn{2}{c}{ Espaçamentos Falhos (\%) } \\
\cline { 2 - 3 } Horizontal que Passaram pelo Tubo Condutor & Sementes Arredondadas & Sementes Achatadas \\
\hline 2.000 & $3,5^{(1)}$ & 1,5 \\
30.000 & 3,4 & 1,9 \\
55.000 & 3,2 & 1,6 \\
\hline Média geral & 3,4 & 1,6 \\
Coeficiente de variação & 32,6 & 36,5 \\
\hline
\end{tabular}

(1) Não-significativos pelo teste "F" (P > 0,05).

A média geral dos espaçamentos falhos das sementes arredondadas foi maior que as achatadas; porém, ambas ficaram dentro dos parâmetros para atingir distribuição longitudinal satisfatória, conforme reportam IRLA \& HEUSSER (1991).

Quando da análise dos espaçamentos múltiplos, as diferenças também se mostraram insignificantes no decorrer da simulação do processo de semeadura, pelo teste "F", com até 55mil orifícios do disco que passaram pelo tubo condutor das sementes (Tabela 2). Portanto, não houve a necessidade da aplicação da regressão polinomial.

Consideraram-se como espaçamentos aceitáveis a resultante da subtração dos espaçamentos falhos e múltiplos do total contabilizado. Assim, como nos parâmetros anteriormente analisados, as diferenças não foram significativas (Tabela 3). A média geral dos espaçamentos aceitáveis das sementes arredondadas foi menor que as achatadas, todavia ambas apresentaram distribuição longitudinal aceitável, pela classificação apresentada por IRLA \& HEUSSER (1991). Portanto, o mecanismo dosador não selecionou sementes maiores, tendo como conseqüência a constância na quantidade de espaçamentos aceitáveis durante a simulação do processo de semeadura.

Como não há regulamentação que estipule a variação-limite do tamanho de sementes de uma mesma peneira, julgou-se como aceitável - principalmente em trabalhos científicos - uma variação máxima de $\pm 10 \%$ em relação à média, tanto para comprimento como para espessura.

TABELA 2. Espaçamentos múltiplos para as sementes de milho arredondadas (híbrido 3021, peneira R2M) e achatadas (híbrido D766, peneira C2L) durante a simulação da semeadura com os discos perfurados horizontais NA11,5R (anel VDE001) e MRE14R (anel AM000), respectivamente.

\begin{tabular}{ccc}
\hline Número de Orifícios do Disco Perfurado & \multicolumn{2}{c}{ Espaçamentos Múltiplos (\%) } \\
\cline { 2 - 3 } Horizontal que Passaram pelo Tubo Condutor & Sementes Arredondadas & Sementes Achatadas \\
\hline 2.000 & $3,0^{(1)}$ & 0,8 \\
30.000 & 2,5 & 0,8 \\
55.000 & 2,5 & 1,0 \\
\hline Média geral & 2,7 & 0,8 \\
Coeficiente de variação & 39,6 & 49,0 \\
\hline
\end{tabular}

(1) Não-significativos pelo teste "F" (P > 0,05). 
TABELA 3. Espaçamentos aceitáveis para as sementes de milho arredondadas (híbrido 3021, peneira R2M) e achatadas (híbrido D766, peneira C2L) durante a simulação da semeadura com os discos perfurados horizontais NA11,5R (anel VDE001) e MRE14R (anel AM000), respectivamente.

\begin{tabular}{ccc}
\hline Número de Orifícios do Disco Perfurado & \multicolumn{2}{c}{ Espaçamentos Aceitáveis (\%) } \\
\cline { 2 - 3 } Horizontal que Passaram pelo Tubo Condutor & Sementes Arredondadas & Sementes Achatadas \\
\hline 2.000 & $93,7^{(1)}$ & 97,8 \\
30.000 & 94,1 & 97,4 \\
55.000 & 94,3 & 97,5 \\
\hline Média geral & 94,0 & 97,6 \\
Coeficiente de variação & 2,2 & 0,6 \\
\hline
\end{tabular}

(1) Não-significativos pelo teste "F" (P > 0,05).

No caso do comprimento das sementes arredondadas, $40 \%$ dessas estavam fora da faixa considerada como tolerável, com $10 \%$ de comprimento acima do diâmetro do orifício do disco $(11,5 \mathrm{~mm})$. Já em se tratando da espessura, $55 \%$ do lote estava fora da faixa considerada como admissível, apresentando $22 \%$ das sementes da peneira com espessura maior que a soma do disco $(4,0 \mathrm{~mm})$, o rebaixamento do anel $(1,8 \mathrm{~mm})$ e o espaço entre o disco e os gatilhos raspadores $(1,5 \mathrm{~mm})$ (Figura 1).
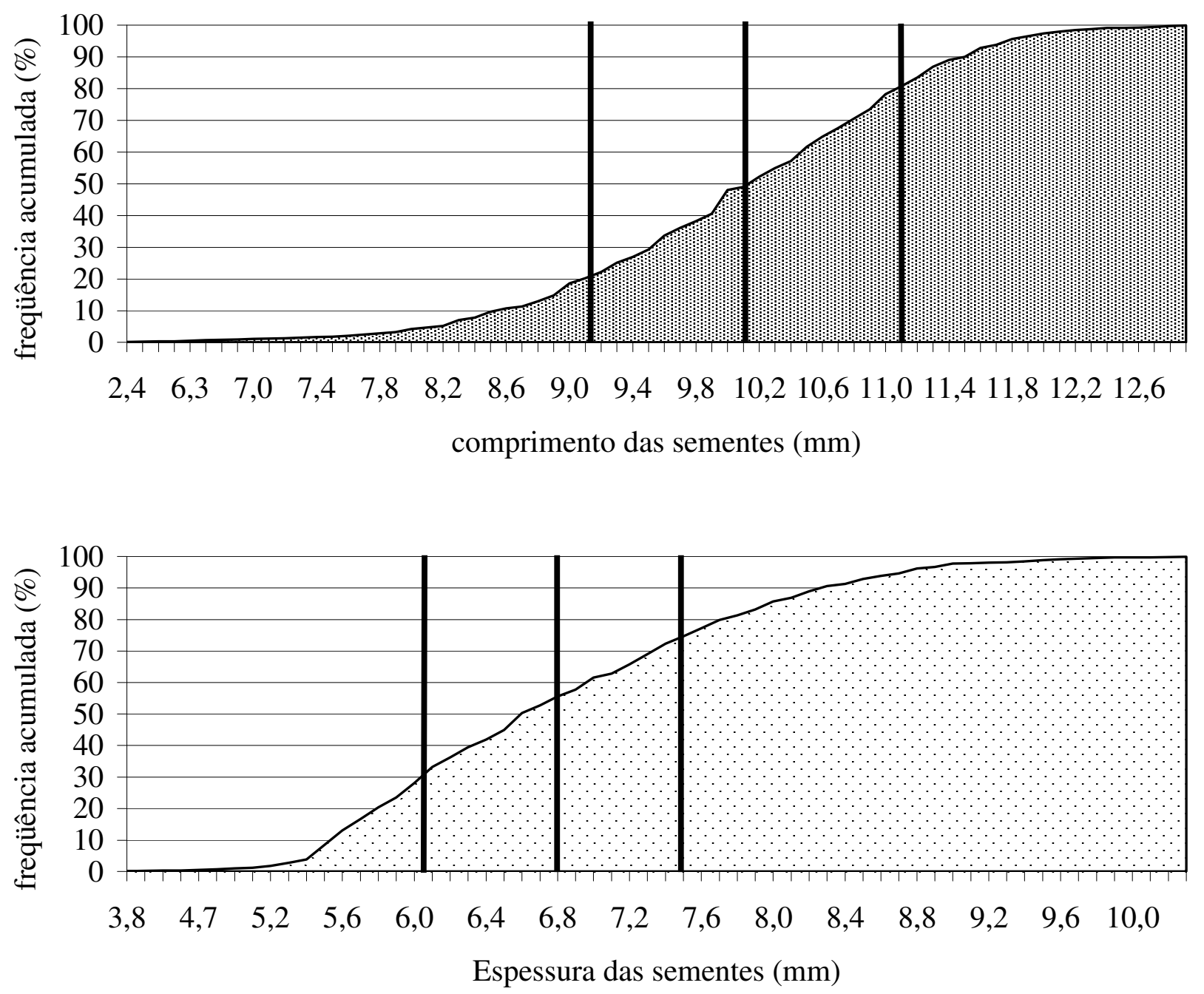

FIGURA 1. Frequiência acumulada do comprimento e espessura das sementes de milho arredondadas (híbrido 3021, peneira R2M), com variação de $\pm 10 \%$ em relação à média. 
Verificando o comprimento das sementes achatadas, concluiu-se que $20 \%$ dessas estavam fora da faixa considerada como tolerável, com $5 \%$ de comprimento maior que o diâmetro do orifício $(14,0 \mathrm{~mm})$. Analisando a espessura, percebeu-se que $50 \%$ do lote ficou fora da faixa considerada como admissível, apresentando 5\% das sementes da peneira com espessura maior que a soma do disco $(4,0 \mathrm{~mm})$ mais o espaço entre o disco e os gatilhos raspadores (1,5 mm) (Figura 2).
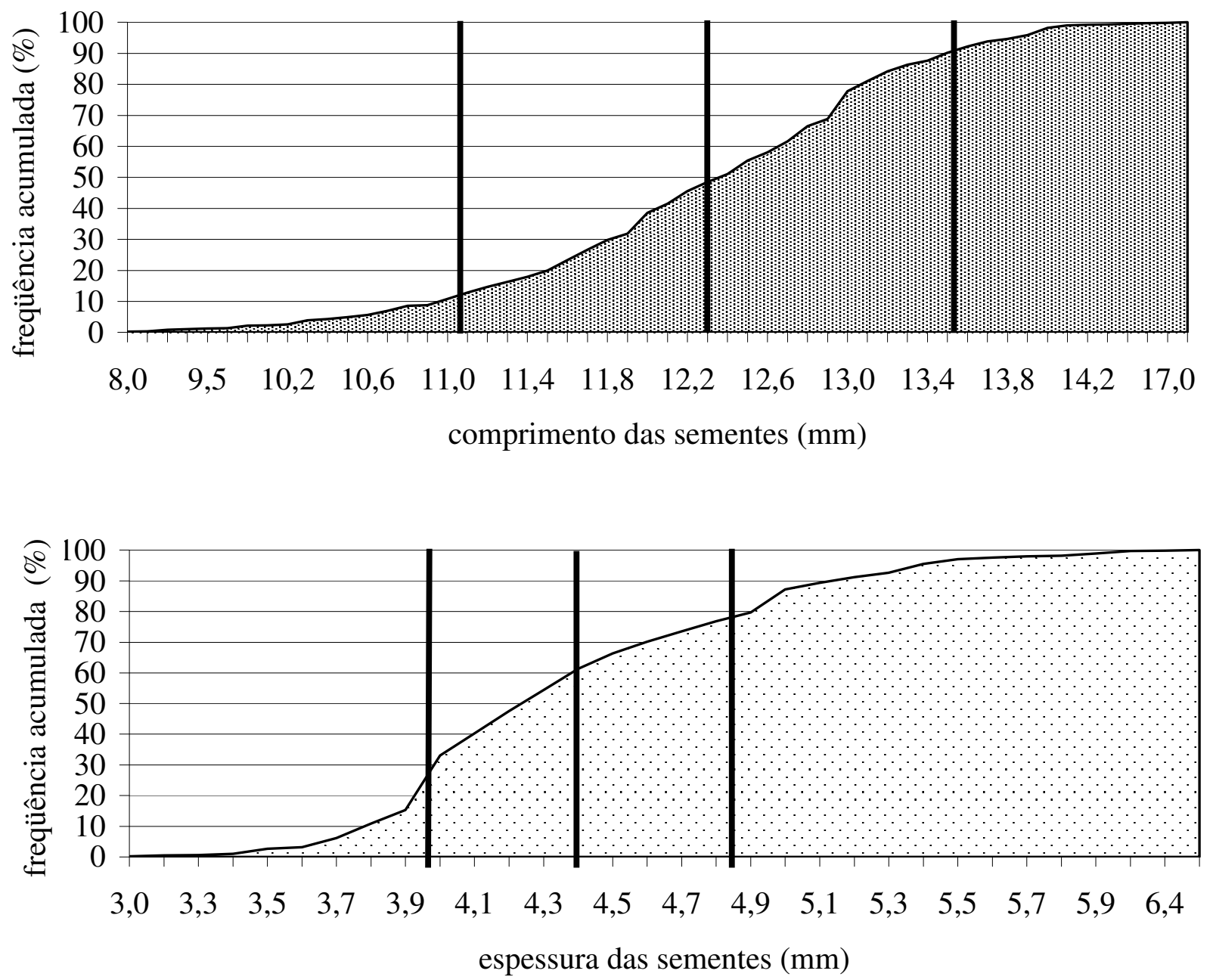

FIGURA 2. Freqüência acumulada do comprimento e espessura das sementes de milho achatadas (híbrido D766, peneira C2L), com variação de $\pm 10 \%$ em relação à média.

A confrontação dos dados pela comparação do número de orifícios do disco horizontal que passaram pelo sistema dosador, computados pelo sensor, e a quantidade de sementes depositadas no mesmo período do processo não foram significativas.

Com as obtenções dos dados sobre comprimento e espessura das sementes, pode-se empregar o teste "F", que não acusou diferenças significativas para todas as variáveis estudadas (Tabela 4). Assim, não houve necessidade de distinguir as diferenças entre as médias dos tratamentos pela regressão polinomial. Sugere-se que o mecanismo dosador apresente condições suficientes para distribuir todos os tamanhos de sementes presentes nas peneiras submetidas à simulação.

O lote de sementes achatadas apresentou menor variação no tamanho de sementes e maior percentagem de espaçamentos aceitáveis, em comparação com as sementes arredondadas. Portanto, pode-se afirmar que a variação no tamanho de sementes da peneira é inversamente proporcional à qualidade da distribuição longitudinal. Porém, não obstante o comprimento e a espessura da peneira ultrapassarem a variação de $\pm 10 \%$ em relação à média, os espaçamentos falhos, múltiplos e aceitáveis mantiveram-se constantes no processo de semeadura. 
TABELA 4. Média do tamanho das sementes de milho arredondadas (híbrido 3021, peneira R2M) e achatadas (híbrido D766, peneira C2L), durante a simulação da semeadura com os discos perfurados horizontais NA11,5R (anel VDE001) e MRE14R (anel AM000), respectivamente.

\begin{tabular}{lcccc}
\hline Número de Orifícios do Disco & \multicolumn{2}{c}{ Comprimento $(\mathrm{mm})$} & \multicolumn{2}{c}{ Espessura $(\mathrm{mm})$} \\
\cline { 2 - 5 } $\begin{array}{c}\text { Perfurado Horizontal que } \\
\text { Passaram pelo Tubo Condutor }\end{array}$ & Arredondadas & Achatadas & Arredondadas & Achatadas \\
\hline Testemunha & $10,2^{(1)}$ & 12,4 & 6,8 & 4,4 \\
2.000 & 10,0 & 12,3 & 6,8 & 4,3 \\
30.000 & 10,1 & 12,4 & 7,0 & 4,5 \\
55.000 & 10,2 & 12,4 & 6,8 & 4,4 \\
\hline Media geral & 10,1 & 12,4 & 6,9 & 4,4 \\
Coeficiente de variação & 2,2 & 1,4 & 2,5 & 2,4 \\
\hline
\end{tabular}

(1) Não significativos pelo teste "F" (P > 0,05).

Os resultados confirmam as conclusões de SILVA \& MARCOS FILHOS (1982) e PINHO et al. (1995) sobre as diferenças na qualidade da instalação da cultura, conforme o formato da semente. Os dados coletados contrariam as conclusões do estudo de KEPNER et al. (1978) sobre a relação do diâmetro das células distribuidoras e espessura do disco referente às dimensões das sementes empregadas. A não-significância das variáveis em estudo pode ser atribuída à ação do mecanismo dosador, que força a passagem das sementes pelos orifícios dos discos (principalmente pela ação dos roletes e gatilhos raspadores).

Com base nos resultados, descartou-se a hipótese de seleção de sementes e alteração na qualidade da distribuição longitudinal de sementes de milho, pelo mecanismo dosador munido de disco perfurado horizontal.

\section{CONCLUSÕES}

Até a passagem de 55 mil orifícios pelo tubo condutor, não houve alterações significativas no tamanho das sementes e distribuição longitudinal, indicando que não houve seleção de sementes de milho durante a simulação do processo de semeadura com disco perfurado horizontal.

\section{REFERÊNCIAS}

ASSOCIAÇÃO BRASILEIRA DE NORMAS TÉCNICAS. Semeadora de precisão: ensaio de laboratório/método de ensaio. Projeto de norma 12:02.06-004. Rio de Janeiro, 1989. 21 p.

BANZATTO, D.A.; KRONKA, S.N. Experimentação agrícola. 3.ed. Jaboticabal: FUNEP, 1995. $247 \mathrm{p}$.

CHHINNAN, M.S.; YOUNG, J.H.; ROHRBACK, R.P. Accuracy of seed spacing in peanuts planting. Transactions of the ASAE, St. Joseph, v.18, n.5, p.828-31, 1975.

DELAFOSSE, R.M. Máquinas sembradoras de grano grueso; descripción y uso. Santiago de Chile: FAO, 1986. 48 p.

FEY, E. Avaliação da distribuição e danos nas sementes de soja (Glycine max (L.) Merrill), sob cultivares e discos, com diferentes velocidades tangenciais do disco dosador. 1998. $45 \mathrm{f}$. Monografia (Trabalho de Graduação em Agronomia) - Universidade Estadual de Ponta Grossa, Ponta Grossa, 1998.

GAZZOLA, O. Projeto e avaliação de um sistema dosador de precisão para semeadora a tração animal. 1989. 103 f. Dissertação (Mestrado em Máquinas Agrícolas) - Faculdade de Engenharia Agrícola, Universidade Estadual de Campinas, Campinas, 1989.

IRLA, E.; HEUSSER, J. Essais comparatifs de semoirs monograine. Tänikon: Station Fédérale de Recherches D’économie D’entreprise et de Génie Rural, 1991. 12 p. 
JUSTINO, A.; WEIRICH NETO, P.H.; SANTOS, S.R. dos. Análise da distribuição do conjunto de sete híbridos de milho (Zea mays L.) e sete discos horizontais perfurados. In: CONGRESSO BRASILEIRO DE ENGENHARIA AGRÍCOLA, 27., 1998, Poços de Caldas. Anais... Lavras: Sociedade Brasileira de Engenharia Agrícola, 1998. p.286-8.

KEPNER, R.A.; BAYNER, R.; BARGER, E.L. Principles of farm machinery. New York: John Wiley, 1978. $57 \mathrm{p}$.

KRANZ, J. Measuring plant disease. In: KRANZ, J.; ROTEM, J. (Ed.). Experimental techniques in plant disease epidemiology. Heidelberg: Springer, 1988. p.35-50.

KRZYZANOWSKI, F.C.; FRANÇA NETO, J.B.; COSTA, N.P. Efeito da classificação de sementes de soja (Glycine max (L.) Merrill) por tamanho sobre a qualidade e a precisão de semeadura. Revista Brasileira de Sementes, Brasília, v.13, n.1, p.59-68, 1991.

KURACHI, S.A.H.; COSTA, J.A.S.; BERNARDI, J.A.; COELHO, J.L.D.; SILVEIRA, G.M. Avaliação tecnológica de semeadoras e/ou adubadoras: tratamento de dados de ensaio e regularidade de distribuição longitudinal de sementes. Bragantia, Campinas, v.48, n.2, p.249-62, 1989.

PACHECO, E.P.; MANTOVANI, E.C.; MERTYN, P.J.; OLIVEIRA, A.C. Avaliação de uma semeadora-adubadora de precisão. Pesquisa Agropecuária Brasileira, Brasília, v.31, n.3, p.209-14, 1996.

PINHO, E.V.R. von; SILVEIRA, J.F.; VIEIRA, M.G.G.C. Influência do tamanho e do tratamento de sementes de milho na preservação da qualidade durante o armazenamento e posterior comportamento no campo. Ciência e Prática, Lavras, v.19, n.1, p.30-6, 1995.

ROCHA, F.E.C.; MANTOVANI, E.C.; BERTAUX, S.; GARCIA, J.C. Comparação de semeadoras-adubadoras de milho (Zea mays L.) com relação a preços de aquisição e eficiência operacional. Pesquisa Agropecuária Brasileira, Brasília, v.27, n.5, p.751-7, 1992.

SANTOS, S.R.; WEIRICH NETO, P.H. Estado de arte do processo de distribuição longitudinal de milho (Zea mayz L.) da Cooperativa Agrária Mista de Entre Rios Ltda. In: CONGRESSO BRASILEIRO DE ENGENHARIA AGRÍCOLA, 28., 1999, Pelotas. Anais... Pelotas: Sociedade Brasileira de Engenharia Agrícola, 1998. 1 CD-ROM.

SILVA, J.G.; KLUTHCOUSKI, J.; SILVEIRA, P.M. Desempenho de uma semeadora-adubadora no estabelecimento e na produtividade da cultura do milho sob plantio direto. Scientia Agrícola, Piracicaba, v.57, n.1, p.7-12, 2000.

SILVA, W.A.; MARCOS FILHO, J. Influência do peso e do tamanho das sementes de milho sobre o desempenho no campo. Pesquisa Agropecuária Brasileira, Brasília, v.17, n.12, p.1743-50, 1982. 